\title{
Analysis of Consumption of Energy Drinks by a Group of Adolescent Athletes
}

\author{
Dariusz Nowak $^{1, *}$ and Artur Jasionowski ${ }^{2}$ \\ 1 Department of Nutrition and Dietetics, Faculty of Health Sciences, \\ Nicolaus Copernicus University in Torun, Ludwik Rydygier Collegium Medicum in Bydgoszcz, \\ Dębowa 3, Bydgoszcz 85-626, Poland \\ 2 Department of Theoretical Foundations of Biomedical Sciences and Medical Informatics, \\ Faculty of Pharmacy, Nicolaus Copernicus University in Torun, \\ Ludwik Rydygier Collegium Medicum in Bydgoszcz, Dębowa 3, Bydgoszcz 85-626, Poland; artuja@wp.pl \\ * Correspondence: d.nowak@cm.umk.pl; Tel.: +48-525-855-401; Fax: +48-525-855-403
}

Academic Editor: María M. Morales Suárez-Varela Received: 28 April 2016; Accepted: 5 July 2016; Published: 29 July 2016

\begin{abstract}
Background: Energy drinks (EDs) have become widely popular among young adults and, even more so, among adolescents. Increasingly, they are consumed by athletes, particularly those who have just begun their sporting career. Uncontrolled and high consumption of EDs, in addition to other sources of caffeine, may pose a threat to the health of young people. Hence, our objective was to analyze the consumption of EDs among teenagers engaged in sports, including quantity consumed, identification of factors influencing consumption, and risks associated with EDs and EDs mixed with alcohol (AmEDs). Methods: The study involved a specially designed questionnaire, which was completed by 707 students, 14.3 years of age on average, attending secondary sports schools. Results: EDs were consumed by $69 \%$ of the young athletes, $17 \%$ of whom drank EDs quite often: every day or 1-3 times a week. Most respondents felt no effects after drinking EDs, but some reported symptoms, including insomnia, anxiety, tachycardia, nervousness and irritability. The major determinant of the choice of EDs was taste (47\%), followed by price $(21 \%)$. One in ten respondents admitted to consumption of AmEDs. Among the consequences reported were: abdominal pains, nausea, vomiting, amnesia, headache, and hangover. Conclusions: EDs consumption among adolescent athletes was relatively high. Considering the habit of AmEDs and literature data, it is worth emphasizing that it may lead to health problems in the near future, alcohol- or drug-dependence, as well as other types of risk behaviour.
\end{abstract}

Keywords: adolescent; athletes; caffeine; dependence; energy drinks

\section{Introduction}

Energy drinks (EDs) enjoy worldwide popularity. In 2013, the global market for these beverages was in excess of 39 billion USD. It is estimated that in 2021 the global value of EDs market will exceed 61 billion USD [1]. EDs are a relatively new class of beverages, which may contain caffeine, taurine an amino acid), vitamins of group B and other vitamins, ginseng extract, glucuronolactone (a glucose metabolite), guarana (contains caffeine, theobromin and theophylline), ephedra, yohimbine, Ginkgo biloba, kola nuts, sugars, herbs and L-carnitine [2]. The caffeine content in $100 \mathrm{~mL}$ of a standard energy drink is $32 \mathrm{mg}$, and is higher when guarana and kola nuts are among the ingredients [3]. Consequently, a can of ED may contain nearly $500 \mathrm{mg}$ of caffeine [4], which is much more than that contained in a cup of coffee (50-100 mg caffeine) or a can of cola (40-60 mg) [5]. The highest EDs consumption is among secondary school and university students, decreasing in older age groups. These drinks are consumed by $30 \%-50 \%$ of adolescents, with $31 \%$ of 
12-19-year-olds admitting to regular EDs consumption [6-8]. The consumption of EDs tested in 16 European countries proved to be even higher, approx. $68 \%$ of adolescents (10-18 years) and approx. 18\% of children (3-10 years) report consuming EDs [3]. Safe limits of caffeine consumption have not been determined, but research suggests that the majority of healthy adults can consume up to $400 \mathrm{mg}$ caffeine a day $[9,10]$. Higher consumption has been associated with: insomnia, anxiety, agitation, headache, tachycardia [11], and may lead to hallucinations, migraines, pontine myelinolysis, gastrointestinal upset, rhabdomyolysis, metabolic acidosis, arrhythmias, chest pain, and other cardiovascular complications [12-17]. Very high consumption of caffeine (above $1 \mathrm{~g}$ ) may be a risk factor in depression [18], and a 5-10 g dose is potentially fatal [6]. The high sugar content of some EDs is also problematic. There is 21-34 g sugar in an $8 \mathrm{floz}$ (approx. $240 \mathrm{~mL}$ ) can [19], although it can be as high as 50-60 g [5], which can contribute to obesity and dental caries [19]. Mixing EDs with alcohol consumption (AmEDs) may result in health disorders (mostly from the cardiovascular system) and risk behaviour, such as drinking and driving, sexual abuse [20,21], excessive alcohol consumption, smoking, drug abuse and violence [22-26]. Many young EDs consumers do not know the composition of EDs and do not distinguish them from other sugar-rich soft drinks or beverages addressed to sports people [27]. As a result, about $52 \%$ of adults and $41 \%$ of adolescents consume EDs (1-5 or more cans in relation to a single sport session) before, in association with, or after sports activities $[3,28]$. Caffeinated drinks are frequently consumed by children and adolescents in order to enhance academic achievement and athletic performance. Some young athletes consume caffeinated drinks encouraged by coaches [29]. Our previous study showed that adolescents consumed EDs before and after physical effort (13\% and 10\%, respectively) [30]. Consequently, it seemed interesting to undertake further research considering the consumption of EDs (and determinants) in sports schools.

Our objective was to analyze consumption of EDs among adolescents practising sports, determine the levels of consumption of these drinks, identify factors which stimulate their consumption and analyze threats associated with drinking EDs and AmEDs.

\section{Materials and Methods}

\subsection{Subjects}

The study was carried out in 2013-2014 (autumn/winter season), in 10 junior secondary sports schools (adolescent aged 13-16 years) from two Polish cities (Bydgoszcz and Toruń). The selection of schools in each location was random, aided by a random number generation formula (an MS Excel application). The survey was designed with the double-random method (one class from each school and each year). It was a questionnaire-based study. During preselected breaks between lessons, students received questionnaires designed by the authors of the study. Before filling in the surveys, the students received verbal instructions from assistants. Moreover, each questionnaire contained written tips/prompts. In total, 1000 questionnaires were distributed, having first obtained permission from the Bioethics Committee (KB 585/2012 and KB 484/2014) and consent of the school authorities. In total, 707 questionnaires were returned and analyzed. The remainder (293) were lost to analysis due to the lack of parents' consent, unreturned or incomplete questionnaires.

\subsection{Assessments}

A detailed questionnaire was designed by the authors. The previously validated questionnaire was already used and presented in greater detail in our article, concerning the consumption of EDs among Polish adolescents [30]. It contained questions eliciting such demographic data as the age, gender, place of residence and discipline of sport practised, as well as questions regarding consumption of EDs and other caffeine-containing beverages (coffee, green and black tea, cola beverages). There were also questions about mixing EDs with alcohol, and about health consequences (problems) of drinking EDs and AmEDs. Additionally, the questionnaire tested respondents' knowledge of the composition and effects of EDs, as well as factors which influenced consumption of EDs. 


\subsection{Statistical Analyses}

Statistical analysis of the results was performed using the software programme Statistica (ver. 9.1; StatSoft, Krakow, Poland). The Pearson $\chi^{2}$ test was employed to assess differences in the distribution of frequency of replies. A value of $p<0.05$ was considered significant.

\section{Results}

The questionnaire was completed by 707 students attending sports classes, including 282 female and 425 male participants (average; age 14.3 years; the Body Mass Index (BMI) $20.7 \mathrm{~kg} \cdot \mathrm{m}^{-2}$ ). Among the respondents, nearly $60 \%$ had a normal range BMI, while over $3 \%$ were overweight. Most students lived in cities (88\%), while the percentage of those living in the villages was $12 \%$. Most respondents had an active lifestyle, and 69\% practised some sports every day. Just one in four admitted to doing some sports only once a week. Students attending schools with extended sports curricula most often practised football (218 persons), basketball (165 persons) or volleyball (148 persons). More details are comprised in Table 1.

Table 1. Participants' characteristics.

\begin{tabular}{|c|c|c|c|}
\hline \multicolumn{2}{|c|}{ Socio-Demographic Data } & \multirow{2}{*}{$\begin{array}{l}n \\
3\end{array}$} & \multirow{2}{*}{$\begin{array}{c}\% \\
0.42\end{array}$} \\
\hline \multirow{6}{*}{ Age (years old) } & Under 13 & & \\
\hline & 13 & 182 & 25.74 \\
\hline & 14 & 189 & 26.74 \\
\hline & 15 & 247 & 34.94 \\
\hline & 16 & 85 & 12.02 \\
\hline & Over 16 & 1 & 0.14 \\
\hline \multirow[b]{2}{*}{ Gender } & Female & 282 & 39.89 \\
\hline & Male & 425 & 60.11 \\
\hline \multirow{4}{*}{$\mathrm{BMI}\left(\mathrm{kg} \cdot \mathrm{m}^{-2}\right)$} & $<18.5$ & 232 & 32.81 \\
\hline & $18.5-24.99$ & 420 & 59.41 \\
\hline & $>24.99$ & 23 & 3.25 \\
\hline & No data & 32 & 4.53 \\
\hline \multirow{2}{*}{ Place of residence } & City & 625 & 88.40 \\
\hline & Village & 82 & 11.60 \\
\hline \multirow{2}{*}{ Practising sports } & Yes & 687 & 97.17 \\
\hline & No & 20 & 2.83 \\
\hline \multirow{4}{*}{ Frequency of practising sports } & Daily & 474 & 69.00 \\
\hline & 2-3/week & 41 & 5.97 \\
\hline & 1/week & 166 & 24.16 \\
\hline & less often than 1 / week & 6 & 0.87 \\
\hline \multirow{5}{*}{ Sports discipline } & football & 218 & 30.83 \\
\hline & basketball & 165 & 23.34 \\
\hline & volleyball & 148 & 20.93 \\
\hline & swimming & 109 & 15.42 \\
\hline & other & 67 & 9.48 \\
\hline
\end{tabular}

EDs were consumed by as many as 488 respondents (69\%). This group was composed of 192 female and 296 male (Table 2). Many sports students consumed EDs quite often, every day or 1-3 times a week. This group consisted of 120 (about 17\%), of which 9 individuals, including 8 boys, consumed EDs every day. The remaining students (slightly more than $50 \%$ ) consumed EDs sporadically, 2-3 times a month or less often. This group comprised mostly of persons who consumed EDs once a month (22\%), and consisted of 96 male and 61 female respondents. 
Table 2. Energy drinks (EDs) consumption by adolescent athletes.

\begin{tabular}{ccccc}
\hline Sex & Female (\%) & Male (\%) & Total (\%) & $p$-Value \\
\hline Consumption of energy drinks & $192(68.09)^{*}$ & $296(69.64)^{* *}$ & $488(69.02)^{* * *}$ & \\
Daily & $1(0.35)$ & $8(1.88)$ & $9(1.27)$ & \\
3/week & 0 & $8(1.88)$ & $8(1.13)$ & \\
2/week & $14(4.97)$ & $42(9.88)$ & $56(7.92)$ & \\
1/week & $14(4.97)$ & $33(7.77)$ & $47(6.65)$ & 0.425 \\
2-3/month & $44(15.60)$ & $65(15.29)$ & $109(15.42)$ & \\
1/month & $61(21.63)$ & $96(22.59)$ & $157(22.21)$ & \\
1/year & $48(17.02)$ & $44(10.35)$ & $92(13.01)$ & \\
Less often than 1/year & $6(2.13)$ & 0 & $6(0.85)$ & \\
No data & $4(1.42)$ & 0 & $4(0.56)$ & \\
\hline
\end{tabular}

${ }^{*}$ Female $=282 ;{ }^{* *}$ male $=425 ; * * * n=707$.

Our statistical analysis showed that EDs consumption did not differ significantly $(p=0.425)$ between female and male respondents (Table 3). Among the 488 students consuming EDs, significantly more $(p=0.009)$ came from Torun than from Bydgoszcz. The lack of association of BMI was observed-the same percentage of students (about 68\%) with proper weight or overweight consumed EDs. We observed that the frequency of practising sports did not have any considerable effect on consumption of EDs $(p=0.645)$. Similar percentages of students consumed EDs every day (around 69\%), 2-3 times a week (68\%) or once a week (69\%) (Table 3).

Table 3. Influence of various factors (sex, BMI, city, sports, frequency of practising sports) on EDs consumption by adolescent students attending junior secondary sports schools.

\begin{tabular}{|c|c|c|c|c|}
\hline & & $n$ & $\%$ & $p$-Value \\
\hline \multirow{4}{*}{ Gender } & Female & & & \multirow{4}{*}{0.425} \\
\hline & Yes/No * & $192 / 90$ & $68.09 / 31.91$ & \\
\hline & Male & \multicolumn{2}{|c|}{425} & \\
\hline & Yes/No * & $296 / 129$ & $69.65 / 30.35$ & \\
\hline \multirow{8}{*}{$\mathrm{BMI}\left(\mathrm{kg} \cdot \mathrm{m}^{-2}\right)$} & $<18.5$ & & & \multirow{8}{*}{0.097} \\
\hline & Yes/No * & $157 / 75$ & $67.67 / 32.33$ & \\
\hline & $18.5-24.99$ & & & \\
\hline & Yes/No * & $284 / 136$ & $67.62 / 32.38$ & \\
\hline & $>24.99$ & & & \\
\hline & Yes/No* & $16 / 7$ & $69.57 / 30.43$ & \\
\hline & \multirow{2}{*}{ No data } & \multicolumn{2}{|c|}{32} & \\
\hline & & $31 / 1$ & $96.88 / 3.12$ & \\
\hline \multirow{4}{*}{ City } & Bydgoszcz & \multicolumn{2}{|c|}{481} & \multirow{4}{*}{0.009} \\
\hline & Yes/No * & $314 / 167$ & $65.28 / 34.72$ & \\
\hline & Toruń & & & \\
\hline & Yes/No* & $174 / 52$ & $77.00 / 23.00$ & \\
\hline \multirow{4}{*}{ Sport } & Practises & & & \multirow{4}{*}{0.125} \\
\hline & Yes/No * & $475 / 213$ & $69.04 / 30.96$ & \\
\hline & Does not practise & \multicolumn{2}{|c|}{19} & \\
\hline & Yes/No * & $13 / 6$ & $68.42 / 31.58$ & \\
\hline
\end{tabular}


Table 3. Cont.

\begin{tabular}{|c|c|c|c|c|}
\hline Factors & & $n$ & $\%$ & $p$-Value \\
\hline \multirow{10}{*}{ Frequency of practising sports } & Daily & & & \multirow{8}{*}{0.645} \\
\hline & Yes/No* & $328 / 146$ & $69.20 / 30.80$ & \\
\hline & 2-3/week & \multicolumn{2}{|c|}{41} & \\
\hline & Yes/No * & $28 / 13$ & $68.29 / 31.71$ & \\
\hline & 1/week & \multicolumn{2}{|c|}{166} & \\
\hline & Yes/No* & $114 / 52$ & $68.68 / 31.32$ & \\
\hline & Less than 1 /week & \multicolumn{2}{|c|}{6} & \\
\hline & Yes/No * & $5 / 1$ & $83.33 / 16.67$ & \\
\hline & No data & \multicolumn{2}{|c|}{20} & \\
\hline & Yes/No* & $13 / 7$ & 35.00 & \\
\hline
\end{tabular}

BMI: Body Mass Index. * Yes, consuming EDs; No, not consuming EDs.

Most frequently, the respondents had $250 \mathrm{~mL}$ of ED daily (43\%), although some drank several units daily. Among the students who had EDs every day $(n=9)$, as many as 5 persons consumed more than $750 \mathrm{~mL}$ of EDs. Energy drink consumers $(n=488)$ were asked how much they spent on EDs. Price had a significant effect $(p<0.05)$ on their choice of EDs. Most persons $(n=260)$ spent $0.5-1$ EUR per drink, although some paid $>1$ EUR $(n=99)$. Data analysis revealed that 49 respondents purchased drinks which cost $<0.5$ EUR, 78 said they were unable to recall the price and 2 did not answer the question.

Determinants which guided the consumers when buying EDs were analyzed (Table 4). The respondents could give more than one answer. The main determinant was taste $(47 \%)$, and the second most important factor was price ( $21 \%)$. Other factors were the ingredients of a drink $(14 \%)$ and the holding capacity of a can or bottle ( $8 \%)$. All determinants are presented in more detail in Table 4 .

Table 4. Determinants affecting the purchase of EDs by adolescent athletes.

\begin{tabular}{ccccc}
\hline Determinant & Females & Males & Total & \% \\
\hline Taste & 139 & 196 & 335 & 47 \\
Price & 50 & 100 & 150 & 21 \\
Composition & 37 & 64 & 101 & 14 \\
Can/bottle & 20 & 39 & 59 & 8 \\
capacity & 8 & 26 & 34 & 5 \\
Others & 9 & 17 & 26 & 4 \\
Availability & 11 & 13 & 24 & 3 \\
Packaging & 4 & 10 & 14 & 2 \\
Advertising & 5 & 9 & 14 & 2 \\
Fashion & 3 & 2 & 5 & 1 \\
Influence of friends & & &
\end{tabular}

Questions were asked about the composition and effects of EDs. Most students ( $n=480 ; 70 \%)$ claimed to know the composition of EDs. Both gender $(p=0.0375)$ and place of residence $(p=0.038)$ had some influence on the knowledge of the composition and effect of EDs. More male (73\%) than female $(65 \%)$ respondents said they knew the ingredients. Most often caffeine, sugar and taurine were indicated. Despite apparently knowing the composition of EDs, as many as $25 \%$ admitted to drinking EDs for no particular reason. The most frequent reasons cited were fatigue $(18 \%)$, thirst $(13 \%)$ and sleepiness $(10 \%)$. There was also a group of young athletes who drank EDs prior to $(15 \%)$ or after (13\%) physical effort. Others consumed EDs prior to, or after, mental effort and at parties.

Excessive consumption of EDs may cause worse physical and mental state due to the content of many bioactive substances, such as caffeine and taurine, in these drinks. The study demonstrated 
that as many as 320 persons $(71 \%)$ felt no effects after drinking EDs. In quite a large group of the respondents $(n=128)$, consumption of EDs led to agitation $(n=89)$ or agitation followed by the feeling of tiredness $(n=30)$. There were also respondents who felt unwell or the same as after drinking alcohol (Table 5). Furthermore, an additional question concerned health disorders after consumption of EDs (opportunity to provide free text). In the group of students who reported health problems, 47 persons $(9.6 \%)$ mostly felt such disorders as: abdominal pain (18 persons), arrhythmia (7 persons), nausea (4 persons).

Table 5. Health problems reported by students after EDs consumption.

\begin{tabular}{cccccc}
\hline Health Problem & Females & Males & Total & $\%$ & $p$-Value \\
\hline None & 133 & 187 & 320 & 71.4 & \\
Agitation & 31 & 58 & 89 & 19.9 & \\
First agitated, then tired & 10 & 20 & 30 & 6.7 & 0.667 \\
Tiredness & 2 & 1 & 3 & 0.7 & \\
Feeling unwell & 1 & 1 & 2 & 0.4 & \\
Same as after alcohol & 1 & 3 & 4 & 0.9 & \\
\hline & $* 448$ out of 488 persons consuming EDs answered the question.
\end{tabular}

Another problem arises when EDs are mixed with alcohol (AmEDs). Among the 488 students drinking EDs, 75 admitted to mixing them with alcohol (Table 6). This group comprised more male $(n=53)$ than female respondents $(n=22)$. The impact of gender on drinking EDs with alcohol was greater $(p=0.048)$ than that of the place of residence $(p=0.595)$. It was also found that the type of a sports discipline practised had some effect on mixing EDs with alcohol $(p=0.023)$. AmEDs most often were observed in combat sports (19.5\%), volleyball (17.7\%) and football (15.7\%). In the group of students who admitted to consuming EDs with alcohol, 10 (13\%) felt such disorders as: abdominal pain (4 persons), nausea ( 2 persons), amnesia (1 person), headache and hangover (1 person).

Table 6. Consumption of energy drinks mixed with alcohol (AmEDs) by secondary sports school students $(n=75)$.

\begin{tabular}{ccccc}
\hline Consumption AmEDs & Females & Males & Total & \% \\
\hline Yes & 22 & 53 & 75 & 10.61 \\
No & 260 & 372 & 632 & 89.39 \\
\hline AmEDs vs. gender & & $p=0.048$ & \\
AmEDs vs. city & & $p=0.289$ & \\
AmEDs vs. sports discipline & & $p=0.023$ & \\
\hline
\end{tabular}

Apart from analyzing consumption of EDs, the study dealt with such beverages as coffee, green and black tea and cola-type of drinks. Coffee was consumed by $34 \%$ of the surveyed school students (Table 7). Additionally, high consumption of black tea (64\%) and cola-type of drinks (about $85 \%)$, as well as somewhat lower consumption of green tea $(45 \%)$ were reported. The gender of the respondents had no influence on the consumption of caffeine from other sources than EDs.

The high consumption of EDs and declared knowledge of their composition meant that the students were aware of the harmfulness of these drinks (in total, 640 persons). Within this group, 258 (156 male and 102 female respondents) believed that EDs were harmful, while 382 (230 male and 152 female respondents) claimed that the harmfulness depended on amounts of EDs consumed. Just 45 students ( 27 male and 18 female respondents) stated that EDs were harmless and the difference between male and female respondents was significant $(p=0.002)$. 
Table 7. Consumption of sources of caffeine other than EDs.

\begin{tabular}{cccccc}
\hline Source of Caffeine & Females & Males & Total & $\%$ & $p$-Value \\
\hline Coffee & 277 & 414 & 691 & 100 & \\
Yes & 87 & 150 & 237 & 34.3 & 0.513 \\
No & 190 & 264 & 454 & 65.7 & \\
\hline Black tea & 275 & 411 & 686 & 100 & \\
Yes & 183 & 256 & 439 & 64 & 0.857 \\
No & 92 & 155 & 247 & 36 & \\
Green tea & 279 & 416 & 695 & 100 & \\
Yes & 125 & 188 & 313 & 45.04 & 0.466 \\
No & 154 & 228 & 382 & 54.96 & \\
\hline Colas & 280 & 420 & 700 & 100 & \\
Yes & 240 & 353 & 593 & 84.71 & 0.043 \\
No & 40 & 67 & 107 & 15.29 & \\
\hline
\end{tabular}

\section{Discussion}

Our study reports that $69 \%$ of students practising sports (mainly football, basketball and volleyball) consume EDs. Most often, they consumed $250 \mathrm{~mL}$ daily. The research data were compared with results of studies completed in 16 European countries, in which $68 \%$ of adolescents consume EDs, in amounts of 7 litres a month $[3,28]$. The EFSA research reported a connection between consumption of EDs and practising sports [28]. A study by Magnezi et al. [31] demonstrated an even higher percentage of junior and senior high school students drinking EDs (84.2\%). Another study suggested that consumption of EDs declines with age. For example, $31 \%$ of respondents in a group composed of 12-17-year-olds consumed EDs regularly, but this percentage fell to $22 \%$ among the 25-35-year-olds [32].

In our study, $17 \%$ of sports school students consumed EDs frequently, every day or from 1 to 3 times a week. This group comprised $1.27 \%$ of respondents consuming EDs on a daily basis. Similarly, Gallimberti et al. [33] reported that 1.3\% of adolescents (aged 11 to 13 years) in north-eastern Italy consumed EDs daily. Groups of adolescent students who declared consumption of EDs once a week or once a month were larger in our study $(6.7 \%$ and $22.2 \%$, respectively) than in the Italian report (5.5\% and 6.5\%, respectively) [33]. Moreover, the Polish students practised sports more often than their Italian counterparts ( $97 \%$ vs. $75 \%$ ), but this may be attributed to the type of schools the current study addressed. Another study reported that nearly half of 12-17 year-olds participants admitted they had consumed EDs in the last fortnight [34]. Australian adolescents have also reported drinking EDs-students aged 8-9-year-olds admitted to consuming an ED once a month, once a week or at weekends [27].

In the current research comparable percentages of boys and girls $(69.6 \%$ vs. $68.1 \%)$ consumed EDs. However, another investigation documented that more boys than girls had tried EDs $(90.1 \%$ vs. $78.4 \%$ ), while daily consumption of EDs was also more often popular among boys than among girls ( $41.5 \%$ vs. $26.3 \%$, respectively) [31]. This is confirmed by another study, in which more male than female respondents aged 11-13 consumed EDs [33].

The main decision-making factors when buying EDs was taste ( $47 \%$ ) followed by price (21\%). This finding was previously confirmed by Magnezi et al., who declared that taste was the main contributor to students' making a decision to buy and consume EDs (50.2\%). Other students chose EDs to feel energized (12.7\%), not to fall asleep (11\%) or out of curiosity (5.3\%) [31]. Among our respondents, as many as $25 \%$ had EDs without giving a reason. For some, the decision was driven by the feeling of fatigue $(18 \%)$, thirst $(13 \%)$ or sleepiness $(10 \%)$. We also found a group of adolescents who consumed EDs before, or after, physical or mental effort.

Most $(70 \%)$ of the students attending sports schools who participated in our study reported that they knew the composition and effects of EDs, and pointed to caffeine as the main ingredient. 
Significant discriminating factors among those students were gender and place of residence. More male $(73 \%)$ than female $(65 \%)$ respondents claimed they knew the composition of EDs. Another study reported that a similar percentage of students were aware of the ingredients in EDs (70.9\%), and this relative number increased with age, up to $92.5 \%$ [33]. Magnezi et al. documented that school students were aware of the presence of caffeine in EDs and in other foodstuffs [31]. However, some research indicates that many adolescents aged 12 to 15 years were uncertain about ingredients found in EDs, and could not easily distinguish these beverages from other drinks, such as soft and sports drinks [27]. Being unaware of the composition of drinks can potentially lead to overweight, obesity, dental caries and other long-term health risks [35].

Excessive consumption of EDs can make one feel unwell due to the content of numerous bioactive substances in these drinks, namely, caffeine or taurine. In our survey, $71 \%$ students claimed they felt no adverse effects after consumption of EDs. However, some respondents reported feeling agitated, tired, unwell or the same as after drinking alcohol. Feeling unwell is often caused by excess caffeine, which induces rapid heart-beat (palpitations), raises blood pressure, or leads to anxiety, insomnia, vomiting, irritability and nervousness [27]. Many students were aware that EDs could be harmful for their health. This was indicated by 640 out of the 707 sports school students we investigated. In another study, 518 students (56.7\%) were of the same opinion, while 172 persons (18.8\%) regarded EDs as harmless and 223 (24.4\%) had no opinion [33]. Another problem is caused by the accumulation of caffeine intake from sources other than EDs, typically, coffee, tea or cola-type beverages, which our respondents said they consumed in considerable amounts. We computed that five students who drank EDs every day had a daily intake of caffeine of $400 \mathrm{mg}$ between EDs and other caffeine-containing drinks. This intake is in excess of the maximum daily dose recommended for adults $[5,9,10]$.

Consumption of EDs is associated with numerous negative consequences, such as seizures, anxiety, agitation, insomnia, hallucinations, migraines, headaches, gastrointestinal disorders, acidosis, chest pains and other cardiovascular complications $[8,11,29]$. Rottlaender et al. reported a case of a female patient admitted to hospital after consumption of 6 cans of EDs within $4 \mathrm{~h}$ [36]. Similar cases have occurred after EDs consumption by a 13-year-old girl [9] and a 23-year-old woman [37]. Persons prone to arrhythmia should be particularly cautious [5]. Consumption of EDs was linked to some unhealthy eating habits (higher intake of sweetened soda drinks and avoidance of breakfast), excessive body mass, insomnia, addiction to computer games, obesity, consumption of alcohol and other dangerous substances [38-40]. Parents, guardians and teachers of adolescents should be aware of such risks.

The fact that EDs are mixed with alcohol (AmEDs) causes another serious problem. Among the students surveyed from sports schools, over 10\% $(n=75)$ consumed AmEDs. This groups consisted of far more male students $(n=53)$. It is worth to emphasize that consumption of alcohol by adolescents is illegal procedure. However, alcohol intake by adolescents is nothing new. Gallimberti et al. reports that $31.2 \%$ of $11-13$-year-olds have tried alcohol [33]. Others describe the habit of mixing EDs with alcohol by college students [41,42] and school pupils [30,31,43]. It was demonstrated that $30.1 \%$ of $14-15$-year-olds have consumed AmEDs, and this percentage increases to $47 \%$ among the 16-18-year-olds. The group consuming AmEDs comprised more male (48.8\%) than female (29.5\%) survey participants [31]. Consumption of AmEDs affects the health of young people. In our study, students drinking AmEDs complained of abdominal pains, nausea and vomiting, amnesia, headache and hangover. Such symptoms have been reported in many of the aforementioned studies.

Moreover, mixing EDs with alcohol leads to more aggressive behaviour among adolescents than drinking alcohol alone [44]. Another problem stems from the fact that ED mixed with alcohol masks the effect of ethanol in $55.7 \%$ of consumers and encourages young people to drink alcohol more frequently [31]. This is dangerous because combining EDs with alcohol can favour development of alcohol, tobacco or drug addictions [24-26]. Also, such drinking habit is observed to be associated with risk behaviours, namely, drinking and driving, binge drinking, or sexual abuse $[8,21,25]$. 
High caffeine intake (above $1000 \mathrm{mg}$, or above this threshold value) originating from EDs, colas, tea and coffee may cause stress, panic attacks or depression in teenagers. It has also been reported that male consumers have a lower caffeine sensitivity threshold at which depression may occur [18].

\section{Conclusions}

EDs are highly popular among adolescents attending sports schools. In our study, $69 \%$ of students consumed EDs, $17 \%$ of whom had EDs often, every day or 1 to 3 times a week. This study demonstrated that EDs consumption among adolescent athletes was slightly higher than among students from other schools, which we had analyzed previously [30]. Some students drinking EDs reported health problems, such as: abdominal pain, arrhythmia, nausea. Over $10 \%$ of the respondents mixed EDs with alcohol (AmEDs), a habit most often observed in combat sports volleyball and football. In this group, students admitted to having various health disorders: abdominal pains, nausea, headache, hangover. This study showed that EDs consumption among adolescent athletes was relatively high. Considering the habit of AmEDs and literature data, it is worth emphasizing that it may lead to health problems in the near future, alcohol- or drug-dependence, as well as other types of risk behaviour.

Acknowledgments: The authors wish to thank the assistants (college students), school staff and students who participated in this study.

Author Contributions: Dariusz Nowak participated in the study design, conducted the study, collected the data, helped to statistical analysis and drafted the manuscript. Artur Jasionowski performed the statistical analysis. All authors read and approved the final manuscript.

Conflicts of Interest: The authors declare no conflict of interest.

\section{References}

1. AIM Market Insight. Global Energy Drinks Market: Insights, Market Size, Share, Growth, Trends Analysis and Forecast to 2021. Available online: http://www.researchandmarkets.com/research/mbbjvv/global_ energy (accessed on 23 January 2016).

2. Higgins, J.P.; Ortiz, B.L. Energy drink ingredients and their effect on endothelial function: A review. Int. J. Clin. Cardiol. 2014, 1, 1-6.

3. European Food Safety Authority. EFSA scientific opinion on the safety of caffeine. EFSA J. 2015, 13, 4102.

4. Arria, A.M.; O'Brien, M.C. The high risk of energy drinks. JAMA 2011, 305, 600-601. [CrossRef] [PubMed]

5. Gray, B.; Das, J.K.; Semsarian, C. Consumption of energy drinks: A new provocation test for primary arrhythmogenic diseases? Int. J. Cardiol. 2012, 159, 77-78. [CrossRef] [PubMed]

6. Seifert, S.M.; Schaechter, J.L.; Hershorin, E.R.; Lipshultz, S.E. Health effects of energy drinks on children, adolescents, and young adults. Pediatrics 2011, 127, 511-528. [CrossRef] [PubMed]

7. Sanchis-Gomar, F.; Pareja-Galeano, H.; Cervellin, G.; Lippi, G.; Earnest, C.P. Energy Drink Overconsumption in Adolescents: Implications for Arrhythmias and Other Cardiovascular Events. Can. J. Cardiol. 2015, 31, 572-575. [CrossRef] [PubMed]

8. Higgins, J.P.; Yarlagadda, S.; Yang, B. Cardiovascular Complications of Energy Drinks. Beverages 2015, 1, 104-126. [CrossRef]

9. Dufendach, K.A.; Hornder, J.M.; Bryan, B.C.; Ackerman, M.J. Congenital type I long QT syndrome unmasked by a highly caffeinated energy drink. Heart Rhythm 2012, 9, 285-288. [CrossRef] [PubMed]

10. Higgins, J.P.; Babu, K.M. Caffeine reduces myocardial blood flow during exercise. Am. J. Med. 2013, 126, e1-e8. [CrossRef] [PubMed]

11. Clauson, K.A.; Shields, K.M.; McQueen, C.E.; Persad, N. Safety issues associated with commercially available energy drinks. Pharm. Today 2008, 14, 52-64. [CrossRef] [PubMed]

12. Trabulo, D.; Marques, S.; Pedroso, E. Caffeinated energy drink intoxication. BMJ Case Rep. 2011, 2. [CrossRef]

13. Calabro, R.S.; Italiano, D.; Gervasi, G.; Bramanti, P. Single tonic-clonic seizure after energy drink abuse. Epilepsy Behav. 2012, 23, 384-385. [CrossRef] [PubMed]

14. Nordt, S.P.; Vilke, G.M.; Clark, R.F.; Lee Cantrell, F.; Chan, T.C.; Galinato, M.; Nguyen, V.; Castillo, E.M. Energy drink use and adverse effects among emergency department patients. J. Community Health 2012, 37, 976-981. [CrossRef] [PubMed] 
15. Seifert, S.M.; Seifert, S.A.; Schaechter, J.L.; Bronstein, A.C.; Benson, B.E.; Hershorin, E.R.; Arheart, K.L.; Franco, V.I.; Lipshultz, S.E. An analysis of energy-drink toxicity in the National Poison Data System. Clin. Toxicol. 2013, 51, 566-574. [CrossRef] [PubMed]

16. Newton, B.D.; Okuda, D.T. Pontine myelinolysis following excessive consumption of commercial energy drinks. Neurol. Neuroimmunol. Neuroinflamm. 2015, 2, e91. [CrossRef] [PubMed]

17. Busuttil, M.; Willoughby, S. A survey of energy drink consumption among young patients presenting to the emergency department with the symptom of palpitations. Int. J. Cardiol. 2016, 204, 55-56. [CrossRef] [PubMed]

18. Richards, G.; Smith, A. Caffeine consumption and self-assessed stress, anxiety, and depression in secondary school children. J. Psychopharmacol. 2015, 29, 1236-1247. [CrossRef] [PubMed]

19. Marks, R. Energy Drinks: A Potentially Overlooked Obesity Correlate. Adv. Obes. Weight Manag. Control 2015, 2. [CrossRef]

20. Striley, C.W.; Khan, S.R. Review of the energy drink literature from 2013: Findings continue to support most risk from mixing with alcohol. Curr. Opin. Psychiatry 2014, 27, 263-238. [CrossRef] [PubMed]

21. Spierer, D.K.; Blanding, N.; Santella, A. Energy drink consumption and associated health behaviors among university students in an urban setting. J. Community Health 2014, 39, 132-138. [CrossRef] [PubMed]

22. Miller, K.E. Wired: Energy drinks, jock identity, masculine norms, and risk taking. J. Am. Coll. Health 2008, 56, 481-489. [CrossRef] [PubMed]

23. Arria, A.M.; Caldeira, K.M.; Kasperski, S.J.; O'Grady, K.E.; Vincent, K.B.; Griffiths, R.R.; Wish, E.D. Increased alcohol consumption, nonmedical prescription drug use, and illicit drug use are associated with energy drink consumption among college students. J. Addict. Med. 2010, 4, 74-80. [CrossRef] [PubMed]

24. Trapp, G.S.; Allen, K.L.; O'Sullivan, T.; Robinson, M.; Jacoby, P.; Oddy, W.H. Energy drink consumption among young Australian adults: Associations with alcohol and illicit drug use. Drug Alcohol Depend. 2014, 134, 30-37. [CrossRef] [PubMed]

25. Bonar, E.E.; Cunningham, R.M.; Polshkova, S.; Chermack, S.T.; Blow, F.C.; Walton, M.A. Alcohol and energy drink use among adolescents seeking emergency department care. Addict. Behav. 2015, 43, 11-17. [CrossRef] [PubMed]

26. McKetin, R.; Coen, A.; Kaye, S. A comprehensive review of the effects of mixing caffeinated energy drinks with alcohol. Drug Alcohol Depend. 2015, 151, 15-30. [CrossRef] [PubMed]

27. Costa, B.M.; Hayley, A.; Miller, P. Young adolescents' perceptions, patterns, and contexts of energy drink use. A focus group study. Appetite 2014, 80, 183-189. [PubMed]

28. EFSA. “Energy” Drinks Report. 6 March 2013. Available online: http://www.efsa.europa.eu/en/press/ news/130306.htm (accessed on 8 January 2016).

29. Temple, J.L. Caffeine use in children: What we know, what we have left to learn, and why we should worry. Neurosci. Biobehav. Rev. 2009, 33, 793-806. [CrossRef] [PubMed]

30. Nowak, D.; Jasionowski, A. Analysis of the Consumption of Caffeinated Energy Drinks among Polish Adolescents. Int. J. Environ. Res. Public Health 2015, 12, 7910-7921. [CrossRef] [PubMed]

31. Magnezi, R.; Bergman, L.C.; Grinvald-Fogel, H.; Cohen, H.A. A survey of energy drink and alcohol mixed with energy drink consumption. Isr. J. Health Policy 2015, 55, 1-8. [CrossRef] [PubMed]

32. Simon, M.; Mosher, J. Alcohol, Energy Drinks, and Youth: A Dangerous Mix. Available online: http://alcoholjustice.org/images/stories/EnergyDrinkReport.pdf (accessed on 6 February 2016).

33. Gallimberti, L.; Buja, A.; Chindamo, S.; Vinelli, A.; Lazzarin, G.; Terraneo, A.; Scafato, E.; Baldo, V. Energy drink consumption in children and early adolescents. Eur. J. Pediatr. 2013, 172, 1335-1340. [CrossRef] [PubMed]

34. O'Dea, J. Consumption of nutritional supplements among adolescents. Usage and perceived benifits. Health Educ. Res. 2003, 18, 98-107.

35. Pomeranz, J.L.; Munsell, C.R.; Harris, J.L. Energy drinks. An emerging public health hazard for youth. J. Public Health Policy 2013, 34, 254-271. [CrossRef] [PubMed]

36. Rottlaender, D.; Motloch, L.J.; Reda, S.; Larbig, R.; Hoppe, U.C. Cardiac arrest due to long QT syndrome associated with excessive consumption of energy drinks. Int. J. Cardiol. 2012, 158, e51-e52. [CrossRef] [PubMed]

37. Raghunathan, K.; Patel, R.; Parajuli, R. Energy drink-related supraventricular tachycardia. Am. J. Med. 2008, 121, e3-e4. 
38. Larson, N.; Laska, M.N.; Story, M.; Neumark-Sztainer, D. Sports and energy drink consumption are linked to health-risk behaviours among young adults. Public Health Nutr. 2015, 16, 1-10. [CrossRef] [PubMed]

39. Miyake, E.R.; Marmorstein, N.R. Energy drink consumption and later alcohol use among early adolescents. Addict. Behav. 2015, 43, 60-65. [CrossRef] [PubMed]

40. Poulos, N.S.; Pasch, K.E. Energy drink consumption is associated with unhealthy dietary behaviours among college youth. Perspect. Public Health 2015, 135, 316-321. [CrossRef] [PubMed]

41. Brache, K.; Stockwell, T. Drinking patterns and risk behaviors associated with combined alcohol and energy drink consumption in college drinkers. Addict. Behav. 2011, 36, 1133-1140. [CrossRef] [PubMed]

42. Marczinski, C.A. Alcohol Mixed with Energy Drinks: Consumption Patterns and Motivations for Use in U.S. College Students. Int. J. Environ. Res. Public Health 2011, 8, 3232-3245. [CrossRef] [PubMed]

43. Martz, M.E.; Patrick, M.E.; Schulenberg, J.E. Alcohol Mixed with Energy Drink Use among U.S. 12th-Grade Students: Prevalence, Correlates, and Associations with Unsafe Driving. J. Adolesc. Health 2015, 56, 557-563. [CrossRef] [PubMed]

44. Miller, K.E.; Quigley, B.M.; Eliseo-Arras, R.K.; Ball, N.J. Alcohol Mixed with Energy Drink Use as an Event-Level Predictor of Physical and Verbal Aggression in Bar Conflicts. Alcohol Clin. Exp. Res. 2016, 40, 161-169. [CrossRef] [PubMed]

(C) 2016 by the authors; licensee MDPI, Basel, Switzerland. This article is an open access article distributed under the terms and conditions of the Creative Commons Attribution (CC-BY) license (http://creativecommons.org/licenses/by/4.0/). 